Supporting Information

\title{
Dynamical Collectivity and Nuclear Quantum Effects on the Intermolecular Stretching Mode of Liquid Water
}

Keiichiro Shiraga ${ }^{\dagger, \ddagger^{*}}$, Yasuhiro Fujii $\|$, Akitoshi Koreeda $\|$, Koichiro Tanaka ${ }^{\sharp, s,}$ Takashi Arikawa\# and Yuichi Ogawa ${ }^{\dagger}$

$\dagger$ Graduate School of Agriculture, Kyoto University, Kyoto 606-8502, Japan

* RIKEN Center for Integrative Medical Sciences, Yokohama 230-0045, Japan

II Department of Physical Sciences, Ritsumeikan University, Kusatsu 525-8577, Japan

\# Department of Physics, Graduate School of Science, Kyoto University, Kyoto 606-8502, Japan

$\S$ Institute for Integrated Cell-Material Sciences (iCeMS), Kyoto University, Kyoto 606-8501, Japan
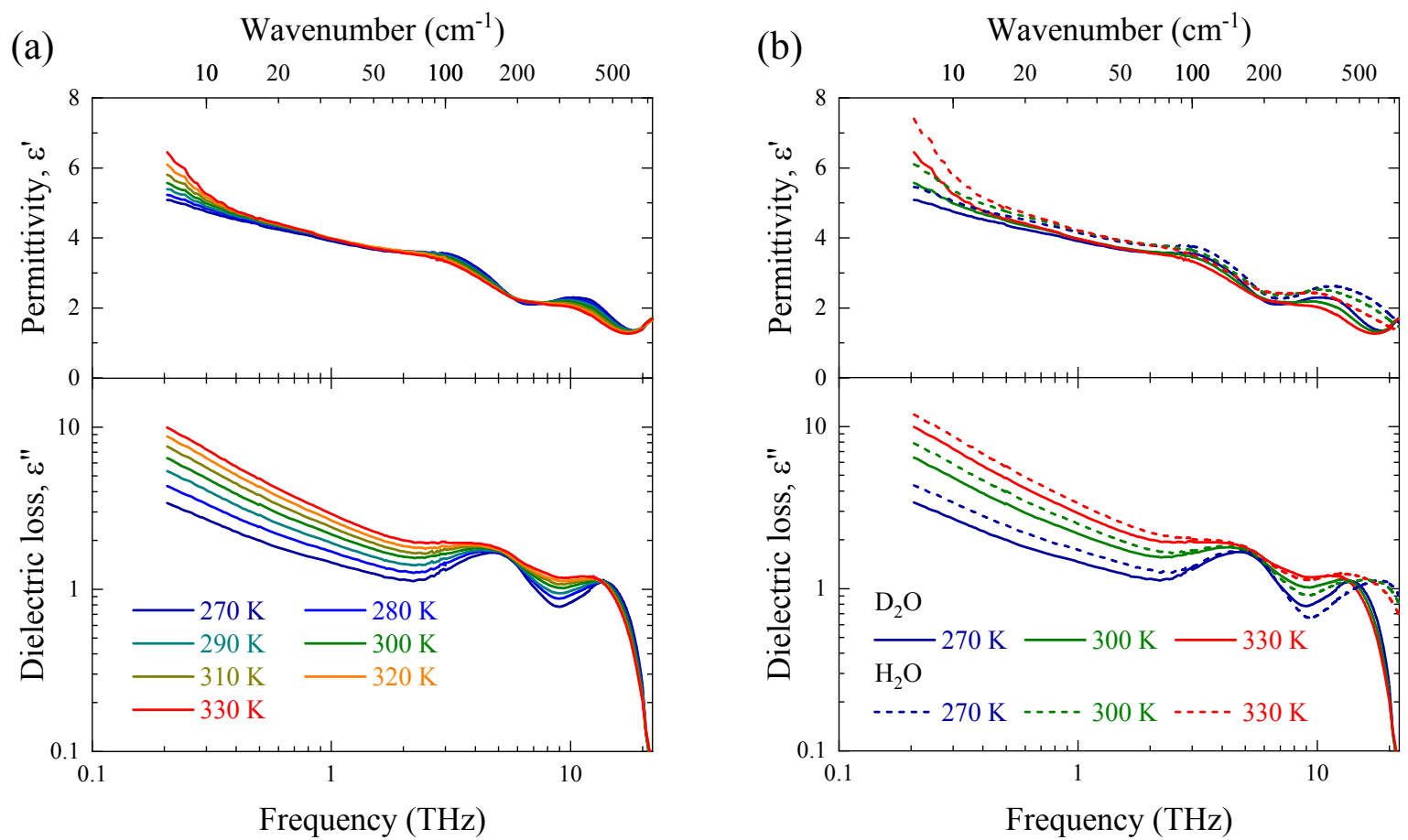

Figure S1. (a) Complex dielectric spectrum of liquid $\mathrm{D}_{2} \mathrm{O}$ from 270 to $330 \mathrm{~K}$. (b) Comparison between liquid $\mathrm{H}_{2} \mathrm{O}$ and $\mathrm{D}_{2} \mathrm{O}$ at $270 \mathrm{~K}, 300 \mathrm{~K}$ and $330 \mathrm{~K}$. 
(a)

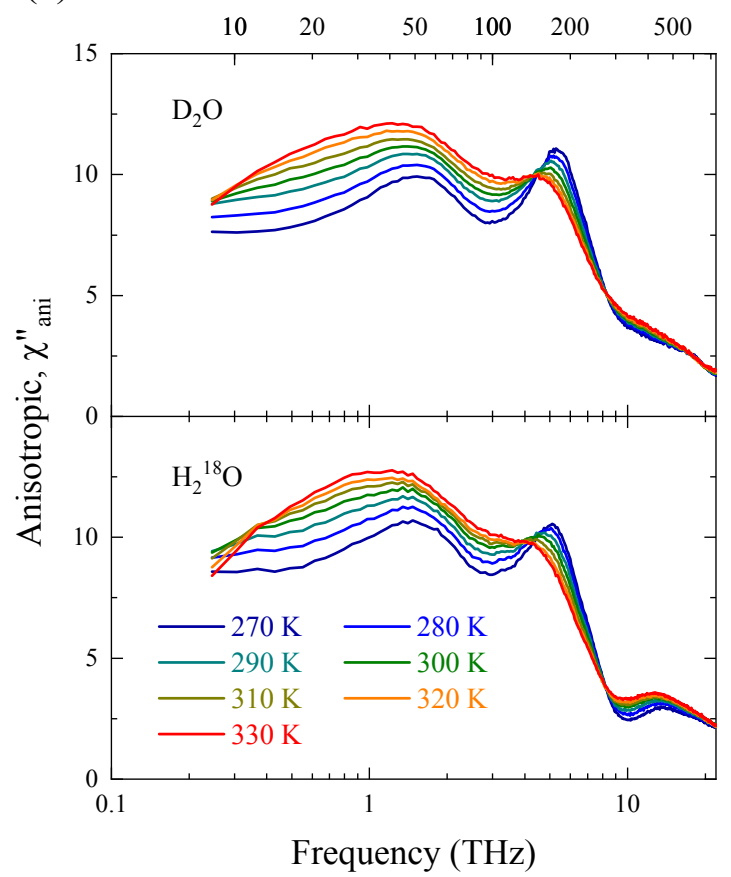

(b) Raman shift $\left(\mathrm{cm}^{-1}\right)$

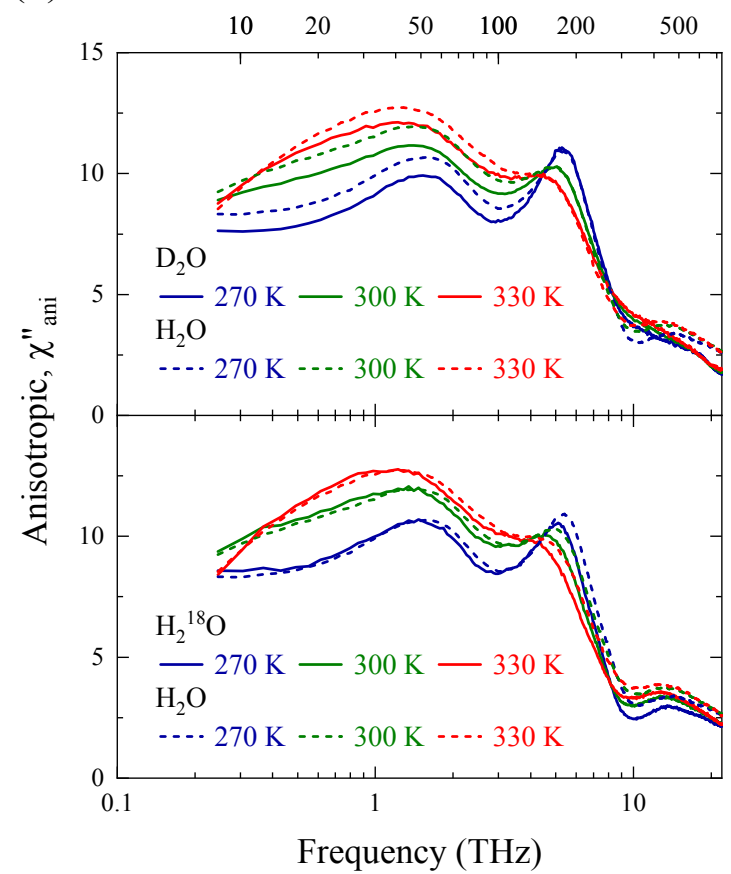

Figure S2. (a) Anisotropic Raman susceptibility spectra of liquid $\mathrm{D}_{2} \mathrm{O}$ and $\mathrm{H}_{2}{ }^{18} \mathrm{O}$ from 270 to $330 \mathrm{~K}$. (b) Comparison with those of liquid $\mathrm{H}_{2} \mathrm{O}$ at $270 \mathrm{~K}, 300 \mathrm{~K}$ and $330 \mathrm{~K}$.

(a)

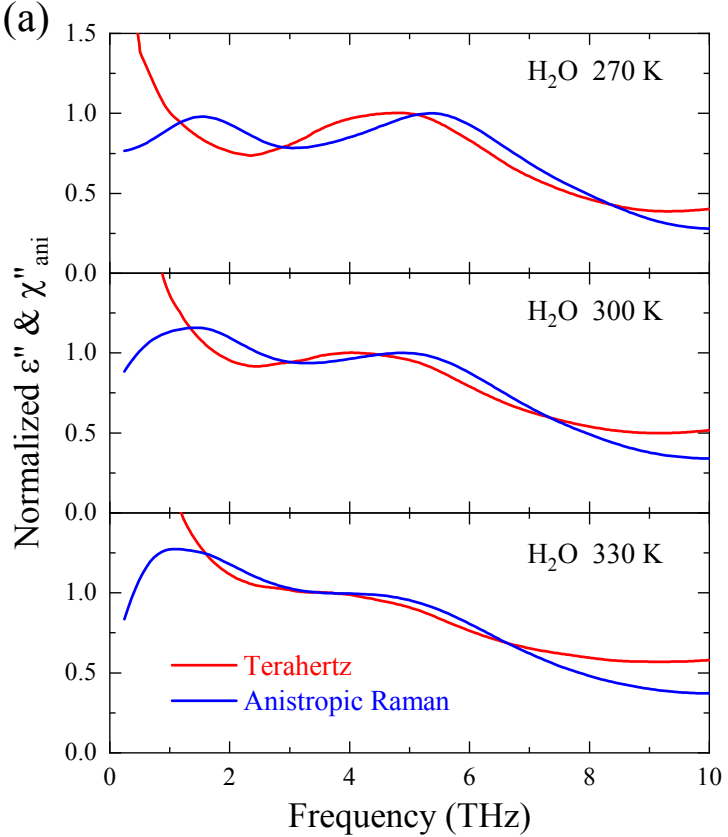

(b)

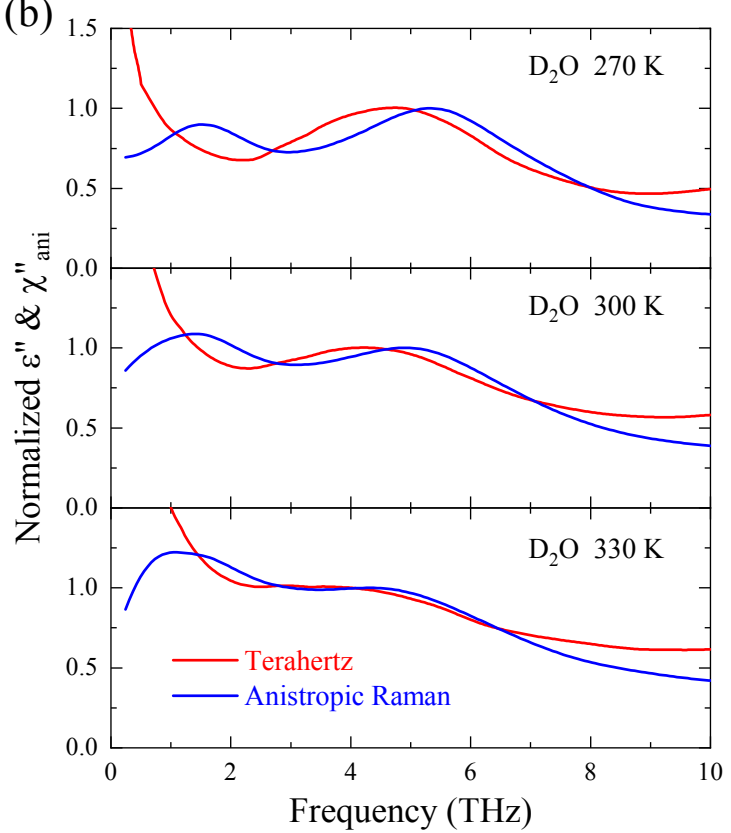

Figure S3. Comparison between the dielectric loss spectrum and anisotropic Raman spectrum of (a) liquid $\mathrm{H}_{2} \mathrm{O}$ and (b) $\mathrm{D}_{2} \mathrm{O}$ at $270 \mathrm{~K}, 300 \mathrm{~K}$ and $330 \mathrm{~K}$. The vertical axis was normalized by the intermolecular stretching peaks around $5 \mathrm{THz}$ in the respective conditions. 